\title{
Targeting TrkB with a Brain-Derived Neurotrophic Factor Mimetic Promotes Myelin Repair in the Brain
}

\author{
이 Jessica L. Fletcher, ${ }^{1}$ Rhiannon J. Wood, ${ }^{1}$ Jacqueline Nguyen, ${ }^{1}$ Eleanor M.L. Norman, ${ }^{1}$ Christine M.K. Jun, ${ }^{1}$ \\ Alexa R. Prawdiuk, ${ }^{1}$ Melissa Biemond, ${ }^{1}$ Huynh T.H. Nguyen, ${ }^{1}$ Susan E. Northfield, ${ }^{2}$ Richard A. Hughes, ${ }^{2}$ \\ David G. Gonsalvez, ${ }^{1}$ OJunhua Xiao, ${ }^{1}$ and ${ }^{\circledR S i m o n ~ S . ~ M u r r a y ~}{ }^{1}$ \\ Departments of ${ }^{1}$ Anatomy and Neuroscience, and ${ }^{2}$ Pharmacology and Therapeutics, School of Biomedical Science, Faculty of Medicine, Dentistry and \\ Health Sciences, The University of Melbourne, Parkville, 3052, Victoria, Australia
}

Methods to promote myelin regeneration in response to central myelin loss are essential to prevent the progression of clinical disability in demyelinating diseases. The neurotrophin brain-derived neurotrophic factor (BDNF) is known to promote myelination during development via oligodendrocyte expressed TrkB receptors. Here, we use a structural mimetic of BDNF to promote myelin regeneration in a preclinical mouse model of central demyelination. In female mice, we show that selective targeting of TrkB with the BDNF-mimetic enhances remyelination, increasing oligodendrocyte differentiation, the frequency of myelinated axons, and myelin sheath thickness after a demyelinating insult. Treatment with exogenous BDNF exerted an attenuated effect, increasing myelin sheath thickness only. Further, following conditional deletion of TrkB from premyelinating oligodendrocytes, we show the effects of the BDNF-mimetic on oligodendrocyte differentiation and remyelination are lost, indicating these are dependent on oligodendrocyte expression of TrkB. Overall, these studies demonstrate that targeting oligodendrocyte TrkB promotes in vivo remyelination in the brain.

Key words: BDNF; CNS; neurotrophins; oligodendrocytes; remyelination; TrkB

Significance Statement

Novel strategies to promote myelin regeneration are required to prevent progressive neurodegeneration and clinical disability in patients with central demyelinating disease. Here, we test whether selectively targeting the TrkB receptor on the myelin-producing oligodendrocytes, can promote remyelination in the brain. Using a structural mimetic of its native ligand, BDNF, we show that stimulation of TrkB enhances remyelination, increasing oligodendrocyte differentiation, the frequency of myelinated axons and thickness of the myelin sheath following a demyelinating insult. Further, we show that these effects are dependent on the phosphorylation of oligodendrocyte expressed TrkB receptors in vivo. Overall, we demonstrate that selective targeting of TrkB has therapeutic potential to promote remyelination in the brain.

\section{Introduction}

Innate myelin regeneration is often incomplete in CNS demyelinating diseases such as multiple sclerosis (MS). This leaves axons exposed, resulting in conduction deficits, loss of metabolic and

\footnotetext{
Received Feb. 20, 2018; revised June 1, 2018; accepted June 25, 2018

Author contributions: J.L.F. wrote the first draft of the paper; J.L.F., J.X., and S.S.M. edited the paper; J.L.F., J.X., and S.S.M. designed research; J.L.F., R.J.W., J.N., E.M.L.N., C.M.K.J., A.R.P., M.B., H.T.H.N., S.E.N., and D.G.G. performed research; R.A,H. contributed unpublished reagents/analytic tools; J.L.F. and S.E.N. analyzed data; J.L.F., J.X., and S.S.M. wrote the paper.

This work was supported by Australian National Health and Medical Research Council (NHMRC) Project Grants (APP1058647 to J.X. and APP1105108 to S.S.M.), a Multiple Sclerosis Research Australia (MSRA) Project Grant (13-039; S.S.M. and J.X.), a MSRA Postdoctoral Fellowship (14-056 to J.L.F.), and a MSRA/NHMRC Early Career Fellowship (APP111041 to D.G.G.). We thank Cameron Nowell (Monash University) and Dr. Verena Wimmer (The Florey Institute) for advice on image analysis procedures and automation. Confocal imaging was performed at the Biological Optical Microscope Platform, The University of Melbourne, and the Florey Advanced Microscopy and Immunohistochemistry Service, The Florey Institute of Mental Health and Neuroscience, and Peter MacCallum Centre for Advanced Histology and Microscopy fassistance with EM processing and imaging.

The authors declare no competing financial interests.
}

trophic support to axons, and contributes to secondary irreversible axonal damage that ultimately drives the progressive clinical disability in patients (Lucchinetti et al., 1999; Chang et al., 2002; Albert et al., 2007). Current commercially available immunomodulatory therapies for MS effectively decrease the frequency of relapses, but do not directly stimulate remyelination (Stangel et al., 2017). As such there is a compelling need to complement these therapies with new strategies to promote myelin regeneration. The neurotrophin brain-derived neurotrophic factor (BDNF) enhances CNS myelination, acting through oligodendrocyte-expressed TrkB

Correspondence should be addressed to either Dr. Jessica Fletcher or Dr. Simon Murray, Department of Anatomy and Neuroscience, School of Biomedical Science, Faculty of Medicine, Dentistry and Health Sciences, The University of Melbourne, Grattan Street, Parkville, 3025, VIC, Australia, E-mail: jessica.fletcher@unimelb.edu.au or ssmurray@unimelb.edu.au.

DOI:10.1523/JNEUROSCI.0487-18.2018

Copyright $\odot 2018$ the authors $\quad 0270-6474 / 18 / 387088-12 \$ 15.00 / 0$ 
receptors (Du et al., 2003; Xiao et al., 2010). Despite the relative potency with which BDNF enhances myelination, its promiscuity to both $\mathrm{p} 75^{\mathrm{NTR}}$ and TrkB receptors, brief half-life (Poduslo and Curran, 1996), large molecular size, and relatively poor ability to cross the blood-brain barrier make it a poor therapeutic candidate, likely contributing to its failure in clinical trials for neurodegenerative disease (The BDNF Study Group, 1999).

To overcome these limitations, a range of small molecular weight neurotrophin receptor agonists have been developed (Longo and Massa, 2013). This includes tricyclic-dimeric peptide-6 (TDP6), a peptide mimetic structurally based on the loop-2 region of the BDNF homodimer that interacts with TrkB (O'Leary and Hughes, 2003). When BDNF binds and activates TrkB, it triggers autophosphorylation of the intracellular domain, recruitment of cytosolic adaptor proteins, and activation of many intracellular signaling cascades, including PI3K/Akt and MAPK/Erk (Chao, 2003). We have previously shown that TDP6, like BDNF, enhances oligodendrocyte myelination in vitro, and does this through phosphorylation of oligodendrocyte-expressed TrkB receptors (Wong et al., 2014).

There is a clinical need to develop remyelinating therapies capable of complementing existing immunomodulatory treatments for MS. Here we test whether oligodendrocyte expressed TrkB receptors are a rational target to achieve this, by assessing whether TDP6 promotes myelin repair in vivo. We show infusion of TDP6, but not BDNF, into the CNS increased oligodendrocyte differentiation, the frequency of myelinated axons and myelin sheath thickness in the cuprizone model of toxic demyelination. Importantly, we demonstrate that this effect is driven by phosphorylation of oligodendrocyte expressed TrkB receptors in vivo. These data suggest selective targeting of TrkB is a rational approach to promote myelin repair in vivo.

\section{Materials and Methods}

Experimental animals and cuprizone-induced demyelination. Female C57BL/6 mice, aged $8-10$ weeks were fed $0.2 \%$ cuprizone in normal chow (Teklad Custom Research Diets) for 6 weeks to induce demyelination. Cuprizone feed was removed and mice were killed or received intracerebroventricular osmotic pumps for $7 \mathrm{~d}$.

For experiments in conditional knock-out mice, 8- to 10-week-old $\mathrm{CNPaseCre}^{+/-}$female progeny of CNPaseCre ${ }^{+/-}$mice (Lappe-Siefke et al., 2003) crossed to TrkB ${ }^{\mathrm{f} / \mathrm{fl}}$ mice (Lulkart et al., 2005) bred to a C57BL/6 background for five generations, underwent procedures described above. Additional $\mathrm{Cre}^{-1-}$ and $\mathrm{Cre}^{+/-}$female mice aged $14-16$ weeks were used as healthy controls.

All mice were housed in specific pathogen-free conditions at the Melbourne Brain Centre Animal Facility. All animal procedures were approved by The Florey Institute for Neuroscience and Mental Health Animal Ethics Committee and followed the Australian Code of Practice for the Care and Use of Animals for Scientific Purposes.

Intracerebroventricular delivery of BDNF and TDP6. Following cuprizone feeding, mice received either $4 \mu \mathrm{M}$ BDNF carried in $0.1 \%$ BSA in artificial CSF (aCSF; $n=8), 40 \mu \mathrm{M}$ TDP6 in aCSF $(n=9)$ or the aCSF vehicle $(n=7)$ via intracerebroventricular osmotic pumps with a flow rate of $0.5 \mu \mathrm{l} / \mathrm{h}$ (ALZET). Infusion concentrations were based on effective concentrations of BDNF and TDP6 in previously published in vitro myelination assays (Wong et al., 2014). Cannulae were implanted at coordinates $+0.5 \mathrm{~mm}$ rostral and $-0.7 \mathrm{~mm}$ lateral of bregma to administer into the right lateral ventricle. Anesthesia was induced with $4-5 \%$ isoflurane and $0.5 \%$ oxygen, and maintained at $2.5-1 \%$ isoflurane and $0.5 \%$ oxygen through a nose cone during stereotaxic manipulation. All mice were placed in a recovery chamber maintained at $32^{\circ} \mathrm{C}$ and monitored immediately following surgery for adverse reactions, and then daily. After $7 \mathrm{~d}$ of continuous infusion, mice were killed and the brain removed for immunostaining and electron microscopic (EM) analysis.

Tissue processing and immunofluorescence. Mice were anesthetized and transcardially perfused with $0.1 \mathrm{~m}$ sterile mouse isotonic $\mathrm{PBS}$ followed by
$4 \%$ paraformaldehyde (PFA). Brains were collected and postfixed in $4 \%$ PFA overnight. The first millimeter of the right hemisphere from the sagittal midline (Fig. 1B) was selected using a sagittal mouse brain matrix and placed in Kanovsky's buffer overnight and washed in $0.1 \mathrm{~m}$ sodium cacodylate before embedding in epoxy resin at the Peter MacCallum Centre for Advanced Histology and Microscopy for EM analysis. The left hemisphere (Fig. 1B) was cryoprotected in 30\% sucrose and frozen in OCT in isopentane over dry ice.

Sagittal sections were cut at $10 \mu \mathrm{m}$ using a cryostat maintained between -20 to $-17^{\circ} \mathrm{C}$ and collected on Superfrost + slides, air-dried and stored at $-80^{\circ} \mathrm{C}$ until use. Approximately $70-100 \mu \mathrm{m}$ separated adjacent sections on each slide. Sections cut beyond $\pm 2.64 \mathrm{~mm}$ lateral from the midline were excluded.

For immunofluorescence, slides were washed in PBS before overnight incubation at room temperature with primary antibodies diluted in $10 \%$ normal donkey serum (NDS) with $0.3 \%$ Triton X-100. Slides were washed in PBS before $2 \mathrm{~h}$ incubation with the appropriate fluorophoreconjugated secondary antibody in the dark. After washing with PBS, slides were counterstained with nuclear marker Hoechst 33442 and coverslipped using aqueous mounting media (Dako). For all stains, immunohistochemistry was performed in batches.

Antibodies used were as follows: rat anti-myelin basic protein (MBP; 1:200; MAB386, Millipore) as a marker for remyelination, rabbit antiOlig2 (1:200; AB9610, Millipore), mouse anti-CC1 (1:200; APC, OP80, CalBioChem), goat anti-platelet derived growth factor receptor- $\alpha$ (PDGFR $\alpha$; 1:200; AF1062, R\&D Systems) to identify stages of the oligodendrocyte lineage, goat anti-Ibal (1:200; ab5076, Abcam) for microglia and mouse anti-glial fibrillary acidic protein (GFAP; 1:100; MA360, Millipore) for astrocytes. Rabbit anti-Ki67 (1:200; RM-9160, Thermo Scientific) was used to assess cell proliferation following heat-induced antigen retrieval with citrate buffer $(10 \mathrm{~mm}, \mathrm{pH}$ 6). To identify the level of TrkB expression rabbit anti-TrkB (1:500; R-149-100, Biosensis) was used, and TrkB activation was detected with antibodies against phosphorylated $\operatorname{TrkB}$ (pTrkB ${ }^{\mathrm{S} 478} ; 1: 200$; R-1718-50, Biosensis).

For MBP immunostaining sections were postfixed with ice-cold $100 \%$ methanol for $10 \mathrm{~min}$ before the first wash. For $\mathrm{pTrkB}^{\mathrm{S} 478}$, tris-based saline with $0.3 \%$ Triton X-100 was used for all washes and the antibody diluent contained $1 \%$ bovine serum albumin in addition to $10 \%$ NDS and primary antibody incubation was performed overnight at $4{ }^{\circ} \mathrm{C}$.

Electron microscopy and analysis. Semithin $(0.5-1 \mu \mathrm{m})$ sections of the caudal corpus callosum in a sagittal plane were collected on glass slides and stained with $1 \%$ toluidine blue. Ultrathin $(0.1 \mu \mathrm{m})$ sections were subsequently collected on $3 \times 3 \mathrm{~mm}$ copper grids. Specimens were examined using JEOL 1011 transmission electron microscope, and images were collected using MegaView III CCD cooled camera operated with iTEM AnalySIS software (Olympus Soft Imaging Systems). Six distinct fields-of-view were imaged at 10,000 $\times$ magnification per animal. Images were used to count myelinated axons, measure axon diameters, myelin thickness, and g-ratios in FIJI/Image (ImageJ 1.51K, NIH). A minimum of three fields-of-view $\left(142 \mu \mathrm{m}^{2}\right)$ were examined per animal with three to four mice per treatment group. For g-ratios, at least 100 axons from three mice per group were measured. Resin embedding, sectioning, poststaining, and EM imaging were performed at the Peter MacCallum Centre for Advanced Histology and Microscopy.

Fluorescence imaging and analysis. All imaging was performed blinded to treatment group and restricted to the caudal region of the corpus callosum, $\sim-1.1$ to $-3.0 \mathrm{~mm}$ from bregma (Fig. $1 C$ ). Analysis was restricted to the splenium of the corpus callosum; tracts contributing to the dorsal hippocampal commissure were excluded. For each analysis, a minimum of three sections per animal were imaged.

To quantify the level of remyelination images of MBP-stained sections were collected with an AxioVision $\mathrm{Hr}$ camera attached to a Zeiss Axioplan2 epifluorescence microscope under a $20 \times$ objective. Uniform exposure times were used.

Remaining analyses were performed using images acquired with a Zeiss LSM780 or LSM880 confocal microscope with 405, 488, 561, and $633 \mathrm{~nm}$ laser lines. For each fluorescent stain, uniform settings were used.

MBP and GFAP staining were quantified as described by Fletcher et al. (2014) using the threshold function in FIJI/ImageJ and limited to a stan- 

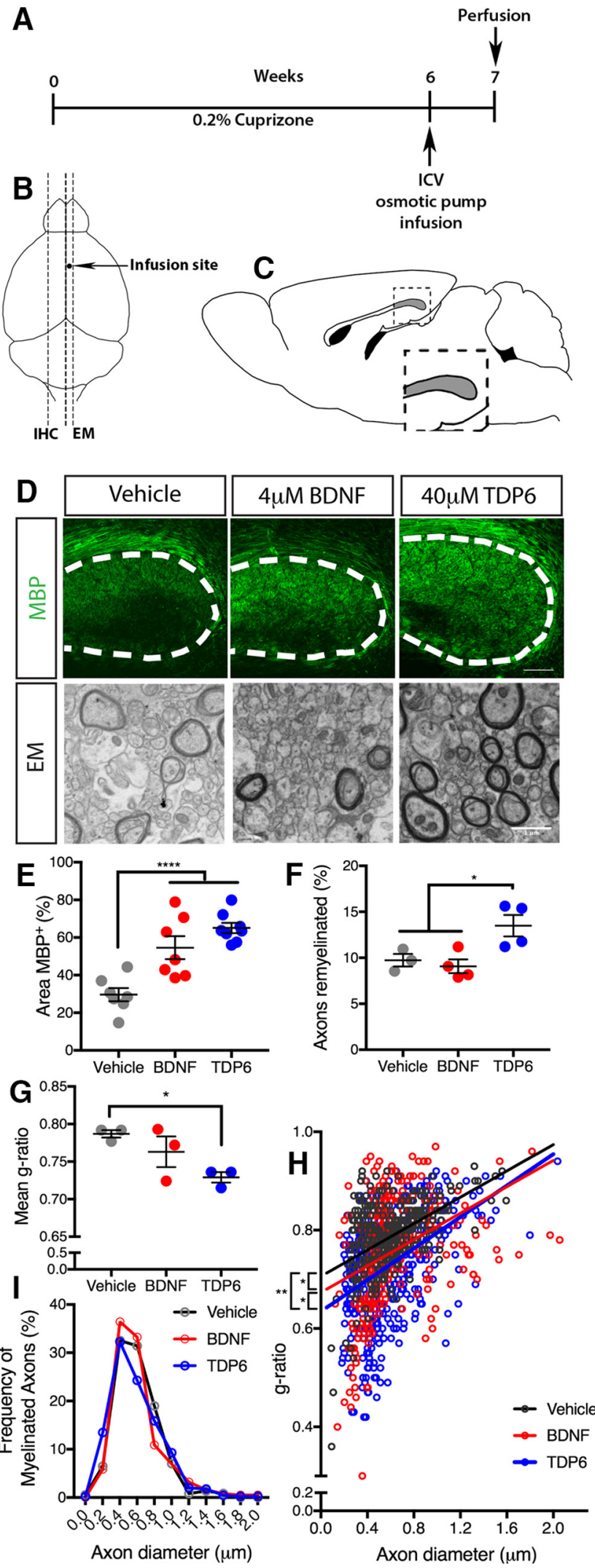

Figure 1. BDNF and TDP6 treatment enhance remyelination following cuprizone-induced demyelination. $\boldsymbol{A}$, Schematic of experimental procedures. $\boldsymbol{B}$, Schematic of tissue selection; contralateral hemisphere to infusion site was processed for immunohistochemistry, whereas ipsilateral hemisphere was taken for EM. C, Schematic of sagittal brain section $0.36 \mathrm{~mm}$ lateral from midline adapted from Paxinos and Franklin (2001); caudal region of the corpus callosum used for analysis is shaded in gray (inset). $\boldsymbol{D}$, Representative micrographs of MBP immunostaining, dard region-of-interest (ROI) of $625,000 \mu \mathrm{m}^{2}$ for each section. Data were expressed as the percentage area of positive staining in a single ROI.

Cell counts. All cell counts were performed using maximum intensity projection images generated from $z$-stacks. A standard ROI was set $\left(625,000 \mu \mathrm{m}^{2}\right)$ and nuclei masks identified by Hoechst or positive Olig2 staining were segmented and counted in FIJI/ImageJ using the "Analyze Particles ..." function to create masks. The threshold function was then applied to identified positive CC1, PDGFR $\alpha$, Iba1-positive staining and to generate a binary image. Positive nuclei were identified using the Binary Reconstruction plugin (Legland et al., 2016), and counted with the Analyze Particles function. Automated counts were verified by manually counting a subsample of images. For $\mathrm{pTrkB}^{\mathrm{S} 478}$ and Ki67 cell counts were performed manually. Data were expressed as the number of cells per square millimeter or the proportion out of the total number of nuclei.

HPLC and mass spectroscopy analysis of TDP6 after $7 d$ minipump incubation in vivo. TDP6 prepared the day before pump administration (day 0 ) and retrieved from the reservoir of osmotic mini-pumps implanted in conditional knock-out mice (day 7) were analyzed by reversephase HPLC (RP-HPLC), using an Agilent 1200 series unit, fitted with a Phenomenex Luna C8 column $(5 \mathrm{u} ; 50 \times 4.6 \mathrm{~mm})$, running $0-60 \%$ acetonitrile over a $14 \mathrm{~min}$ window. UV spectra were measured for each sample using a $214 \mathrm{~nm}$ wavelength, showing a single TDP6 peptide peak at 7.3 min (Fig. 6). A sample of aCSF was run as a control.

Liquid-chromatography mass spectrometry, using an Agilent 6100 series single quadrupole system, was used to confirm the molecular weight of the peptide, TDP6 showing the predicted $m / z$ of $1207.5[\mathrm{M}+2 \mathrm{H}]^{2+}$.

Experimental design and statistical analyses. All data collection was performed blind to sample identity. To compare between treatment groups, one-way or two-way ANOVA or unpaired Student's $t$ tests were performed with post hoc multiple-comparison tests as appropriate. For each ANOVA the effect size was estimated using $\eta_{p}^{2}$, whereas for $t$ tests Cohen's $d$ and SD were calculated. For g-ratios, linear regressions were performed, and axon diameter frequency distribution was assessed using $\chi^{2}$ distribution tests. All statistical tests were performed in GraphPad Prism 7 with $p<0.05$ considered significant.

\section{Results}

BDNF, and its structural mimetic TDP6, enhance myelin repair following cuprizone-induced demyelination

Having previously shown that BDNF and TDP6 enhance oligodendrocyte myelination in vitro (Wong et al., 2014), here we tested the capacity of BDNF and TDP6 to promote remyelination in vivo. To do this, demyelination was induced in 8- to 10 -weekold female C57BL/ 6 mice with $0.2 \%$ cuprizone in normal chow for 6 weeks (Fig. 1A). Efficacy of cuprizone-induced demyelination was confirmed through EM and immunostaining for MBP in the brains of mice collected at the end of the 6-week cuprizone

\section{$\leftarrow$}

and electron micrographs of myelinated and unmyelinated axons in the caudal corpus callosum of vehicle-, BDNF-, and TDP6-treated mice respectively. Dotted line indicates the boundary of caudal corpus callosum in sagittal plane. MBP micrographs: Scale bar, $20 \mu \mathrm{m}$. EM: Scale bar, 1 $\mu \mathrm{m}$. $\boldsymbol{E}$, Percentage area positive for MBP immunostaining was significantly enhanced in the caudal corpus callosum of mice treated with $4 \mu \mathrm{m}$ BDNF and $40 \mu \mathrm{M}$ TDP 6 for $7 \mathrm{~d}$ after 6 weeks cuprizone demyelination, compared with the vehicle-treated mice ${ }^{* * *} p<0.0001, n=$ 7-9/group). $\boldsymbol{F}$, Percentage of myelinated axons was significantly increased with TDP6, but not BDNF, compared with vehicle-treated controls ( ${ }^{*} p=0.018, n=3-4 /$ group). G, Mean g-ratio was significantly decreased with TDP6 treatment compared with vehicle controls, indicative of thicker myelin sheaths ( ${ }^{*} p=0.019, n=3-4$ /group). $\boldsymbol{E}-\mathbf{G}$, One-way ANOVA with Tukey's post hoc multiple comparisons. Mean \pm SEM plotted. $\boldsymbol{H}$, Scatter-plot of g-ratio against axon diameter. Linear regression analysis revealed a significant decrease in the $y$-intercepts between BDNF and TDP6-treated mice compared with vehicle-treated controls, and between TDP6 compared with BDNF treatment $\left({ }^{*} p=0.0042\right)$, but no significant change in slope $(p=0.45)$. I, Frequency distribution plot of myelinated axon diameters indicating no change with treatment in the frequency of myelinated axons based on size ( $p=0.43, \chi^{2}$ distribution test). $\mathbf{F}-\boldsymbol{I}$, Minimum 150 axons/animal, $n=3$ /group. 
challenge (minimum $n=2 /$ cohort). These mice demonstrated demyelination, with loss of myelin from axons identified by EM and severe reduction in the level of MBP expression within the corpus callosum (data not shown). Remaining mice received 4 $\mu \mathrm{M}$ BDNF, $40 \mu \mathrm{M}$ TDP6, or aCSF vehicle delivered at a rate of 0.5 $\mu \mathrm{l} / \mathrm{h}$ by intracerebroventricular osmotic pump for $7 \mathrm{~d}$ to the right lateral ventricle. Dose was chosen based on our previous in vitro data (Wong et al., 2014). After $7 \mathrm{~d}$ infusion, immunostaining (Fig. 1D) revealed that BDNF and TDP6 significantly increased the area of the contralateral caudal corpus callosum positive for MBP (Fig. $1 E ;{ }^{* \star * *} p<0.001, \eta_{p}^{2}=0.66$ ), indicative of greater remyelination. EM analysis of myelin ultrastructure (Fig. 1D) revealed that in the caudal corpus callosum of mice treated with TDP6, the proportion of myelinated axons was significantly increased compared with vehicle controls (Fig. $1 F ;{ }^{*} p<0.018, \eta_{p}^{2}=$ $0.63)$. In contrast, in those treated with BDNF, the proportion of myelinated axons was similar to those that only received the vehicle (Fig. $1 F$ ). Assessment of myelin sheath thickness by g-ratio revealed that TDP6 treatment significantly reduced the mean g-ratio compared with the vehicle (Fig. $1 G ;{ }^{\star} p=0.019, \eta_{p}^{2}=$ 0.63 ) indicating thicker myelin sheaths. Linear regression indicated that BDNF also significantly increased myelin sheath thickness (Fig. $1 H ;{ }^{\star} p=0.04$ ) compared with the vehicle, but that TDP6 had a more pronounced effect with significantly thicker myelin than both BDNF (Fig. $1 H$; ${ }^{\star} p=0.02$ ) and vehicle treatment (Fig. $1 H ;{ }^{*} p=0.014$ ). There was no change in the frequency distribution of myelinated axons based on axon diameter (Fig. 1I). Overall, these findings indicate TDP6 significantly enhances remyelination in vivo.

\section{Treatment with TDP6, but not BDNF, increases the density of postmitotic oligodendrocytes}

To identify whether BDNF or TDP6 treatment exerted an effect on oligodendroglial subpopulations, we next examined the density of total Olig2 ${ }^{+}$oligodendroglia, Olig2 ${ }^{+} \mathrm{PDGFR} \alpha{ }^{+}$ oligodendrocyte progenitor cells (OPCs) and postmitotic Olig ${ }^{+} \mathrm{CC}^{+}$oligodendrocytes in the caudal corpus callosum using immunohistochemistry (Fig. $2 A$ ). The density of Olig2 ${ }^{+}$ oligodendroglia was significantly increased with TDP6 treatment, above that seen with BDNF or vehicle treatment (Fig. $2 B$; $\left.{ }^{\star} p=0.024, \eta_{p}^{2}=0.30\right)$. Examination of the contribution of OPCs to this increase in oligodendroglia, revealed there was no significant change in the density of Olig $2^{+}$PDGFR $\alpha^{+}$OPCs in mice treated with TDP6 compared with those treated with BDNF or the vehicle (Fig. $2 C ; p=0.06, \eta_{p}^{2}=0.22$ ). In contrast, the density of Olig $2{ }^{+} \mathrm{CC}^{+}{ }^{+}$oligodendrocytes in TDP6-treated mice was significantly increased compared with treatment with BDNF and the vehicle (Fig. $2 D ;{ }^{*} p=0.0051, \eta_{p}^{2}=0.38$ ). To examine whether this increase in postmitotic oligodendrocytes was due to TDP6 exerting an effect on OPC proliferation post-cuprizone, we assessed the proportion of PDGFR $\alpha^{+}$cells colabeled with proliferative cell marker, Ki67. This revealed that TDP6 infusion did not alter the proportion of OPCs proliferating at $7 \mathrm{~d}$ postcuprizone removal ( 6 weeks cuprizone: $0.17 \pm 0.06$; Vehicle: $0.14 \pm 0.08$; TDP6: $0.09 \pm 0.03, p=0.67, \eta_{p}^{2}=0.12$ ). This increased density of oligodendrocytes, but not OPCs, suggests TDP6 may increase overall oligodendrocyte differentiation and/or their survival during remyelination. Together, the increase in oligodendrocyte density is consistent with the increased proportion of remyelinated axons in mice treated with TDP6, but not BDNF.

To determine whether BDNF or TDP6 treatment altered gliosis, the contralateral caudal corpus callosum was immunola- beled with GFAP for astrocytosis and Iba1 for microgliosis (Fig. 2A). Astrocytosis persisted with both BDNF and TDP6 treatments, and the level of GFAP staining was unchanged across the three groups (Fig. $2 E ; p=0.34, \eta_{p}^{2}=0.011$ ). Similarly, the density of Iba1 ${ }^{+}$microglia was unchanged across treatments (Fig. $2 F$; $\left.p=0.34, \eta_{p}^{2}=0.099\right)$. This suggests treatment with either TDP6 or BDNF exerts no reductive effects on neuroinflammatory cell populations, indicating their effect on myelin repair is not secondary to an anti-inflammatory effect.

\section{TDP6 and BDNF increase TrkB phosphorylation in oligodendrocytes during remyelination}

As a structural-mimetic of the loop-2 region of the BDNF homodimer, TDP6 is designed to selectively interact with and initiate phosphorylation of TrkB receptors (O'Leary and Hughes, 2003). Indeed, we have previously shown that TDP6 phosphorylates oligodendrocyte-expressed TrkB receptors and promotes myelination in vitro (Wong et al., 2014). To examine whether BDNF and TDP6 treatment successfully stimulated TrkB phosphorylation in oligodendrocytes in vivo, the contralateral caudal corpus callosum was coimmunolabeled with antibodies directed against the phosphorylated serine 478 of $\operatorname{TrkB}\left(\mathrm{pTrkB}^{\mathrm{S} 478}\right)$, and the oligodendroglial markers CC1 and PDGFR $\alpha$ (Fig. 3A). This revealed that the proportion of total $\mathrm{pTrkB}^{\mathrm{S478+}}$ cells in the corpus callosum was significantly increased following TDP6 infusion, but not BDNF, compared with the vehicle (Fig. $3 B ;{ }^{\star *} p=$ $\left.0.0047, \eta_{p}^{2}=0.49\right)$. Assessing the proportion of $\mathrm{pTrkB}^{\mathrm{S} 478+}$ cells that were PDGFR $\alpha^{+}$OPCs, indicated a trend toward increased $\mathrm{pTrkB}^{\mathrm{S} 478+}$ OPCs in mice treated with TDP6 (Fig. $3 C ; p=0.12$, $\left.\eta_{p}^{2}=0.22\right)$. In PDGFR $\alpha^{+}$cells, $\mathrm{pTrkB}^{\mathrm{S} 478}$ was observed to be colocalized either with PDGFR $\alpha$ or intracellularly (Fig. 3A) in all groups. In contrast, $\mathrm{pTrkB}^{\mathrm{S} 478}$ was only seen intracellularly in $\mathrm{CC}^{+}{ }^{+}$cells. The proportion of CC1-pTrkB ${ }^{\mathrm{S} 478}$ double-positive cells in the corpus callosum was significantly increased in mice treated with BDNF and TDP6 (Fig. $3 D ;{ }^{\star * * *} p<0.0001, \eta_{p}^{2}=$ 0.25 ). These results demonstrate that both BDNF and TDP6 successfully reached their cellular targets following intracerebroventricular delivery, and were capable of phosphorylating TrkB on oligodendrocytes.

\section{Adult myelination and demyelination is unaltered by deletion of oligodendroglial TrkB}

To test whether the pro-remyelinating effect of TDP6 required TrkB expression on oligodendrocytes, we generated mice with an oligodendrocyte-specific deletion of TrkB (Lulkart et al., 2005) driven by the CNPase promoter (Lappe-Siefke et al., 2003; $\mathrm{CNPaseCre}^{+/-} \mathrm{TrkB}^{\mathrm{fl} / \mathrm{fl}}$ mice). These mice had $\sim 3$-fold reduction in Olig $2^{+} \mathrm{TrkB}^{+}$cells in the caudal region of the corpus callosum at 14-16 weeks of age (Fig. $4 A$, quantified in $B$ ).

To assess the effect of TrkB deletion from CNPase-expressing cells on oligodendrocyte density and myelin, we first compared unchallenged conditional knock-out and wild-type littermate mice, then compared the effect of cuprizone-induced demyelination on the two genotypes. Female CNPaseCre ${ }^{-/-} \mathrm{TrkB}^{\mathrm{fl} / \mathrm{fl}}$ and $\mathrm{CNPaseCre}^{+/-} \operatorname{TrkB}^{\mathrm{fl} / \mathrm{fl}}$ mice were unchallenged, or fed $0.2 \%$ cuprizone in normal chow for 6 weeks from 8 to 10 weeks of age, killed and the caudal corpus callosum immunohistochemically analyzed (Fig. 4C). In unchallenged mice, similar levels of MBP staining were observed regardless of genotype, and both genotypes demyelinated to a similar extent following cuprizone (Fig. $4 C$, quantitated in $\left.D ; p_{\text {genotype }}=0.55, \eta_{p}^{2}=0.033\right)$. Similarly, the density of Olig $2^{+}$oligodendroglia (Fig. 4E), Olig $2^{+}$PDGFR $\alpha^{+}$ 

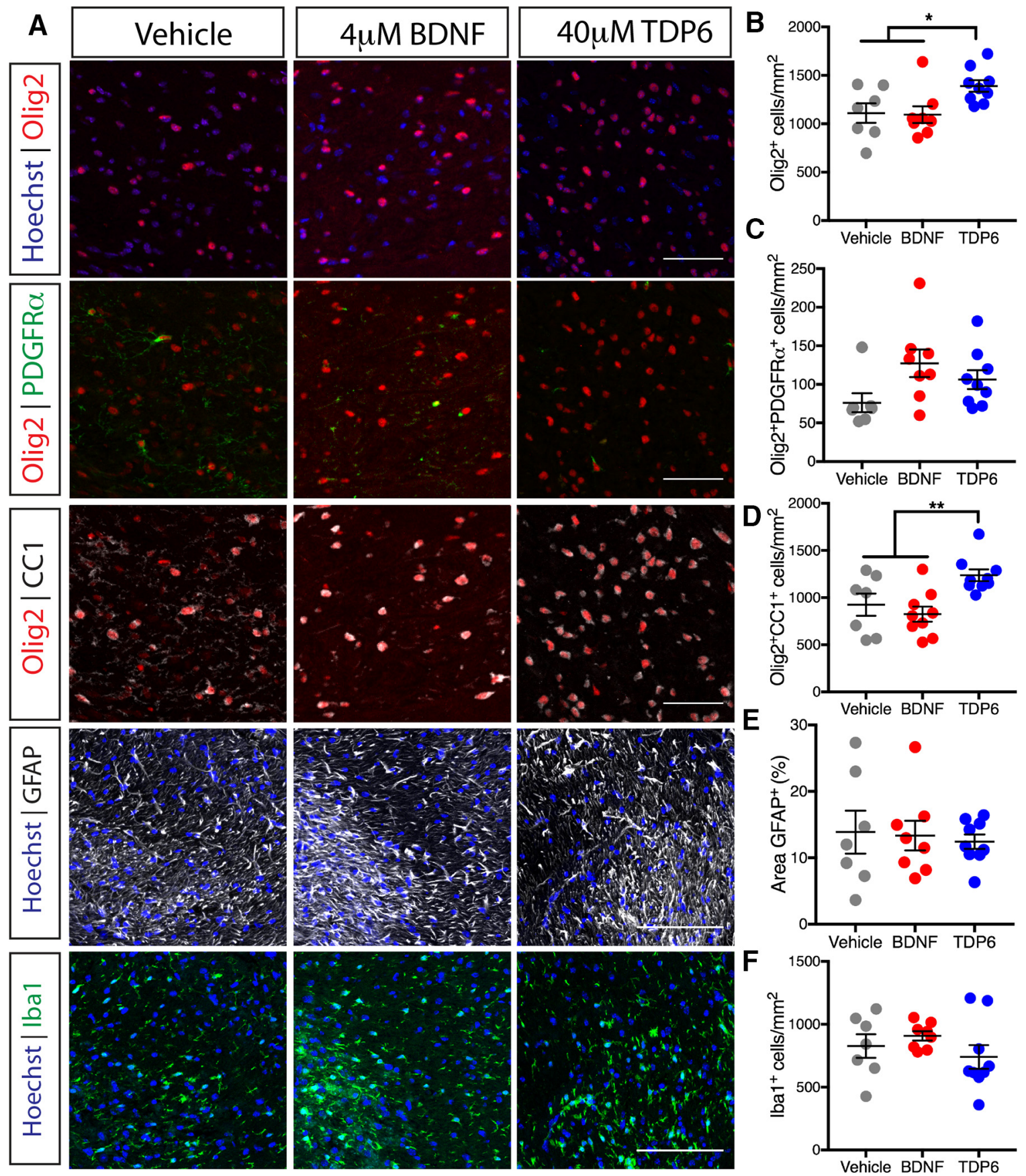

Figure 2. Treatment with TDP6, but not BDNF, enhances oligodendrocyte density and differentiation during remyelination. $A$, Representative micrographs of immunostaining in the caudal region of the corpus callosum for total Olig2 ${ }^{+}$oligodendrocytes, 0 lig2 ${ }^{+} \mathrm{PDGFR} \alpha^{+} \mathrm{OPCs}$, and 0 lig2 ${ }^{+} \mathrm{CC} 1^{+}$oligodendrocytes (Scale bar, $50 \mu \mathrm{m}$ ), as well as GFAP ${ }^{+}$astrocytosis and Iba1 ${ }^{+}$ microglia (Scale bar, $100 \mu \mathrm{m}$ ). B, Density of total Olig2 ${ }^{+}$oligodendrocytes was significantly increased in TDP6-treated mice compared with treatment with BDNF or vehicle $\left({ }^{*} p=0.024\right) . C$, Density of Olig2 ${ }^{+}$PDGFR $\alpha{ }^{+}$OPCs was unchanged across treatments $(p=0.06)$. D, Density of 0 lig ${ }^{+} \mathrm{CC}^{+}$oligodendrocytes significantly increased with TDP6 treatment compared with BDNF and vehicle treatments $\left({ }^{*} p=0.0051\right) . \boldsymbol{E}$, Percentage area of GFAP ${ }^{+}$astrocytes was unchanged across treatments $(p=0.89) . \boldsymbol{F}$, Density of $\mathrm{Iba} 1^{+}$microglia was unchanged across treatments $(p=0.34) . \boldsymbol{B}-\boldsymbol{F}$, $n=7-9 /$ group, one-way ANOVA with Tukey's post hoc multiple comparisons. Mean \pm SEM plotted.

OPCs (Fig. $4 F$ ), and Olig2 ${ }^{+} \mathrm{CC} 1^{+}$oligodendrocytes (Fig. $4 G$ ) was similar in unchallenged mice, with cuprizone exerting no differences between genotypes (Olig2 ${ }^{+}$cells: $p_{\text {genotype }}=0.28$, $\eta_{p}^{2}=0.055 ;$ OPCs: $p_{\text {genotype }}=0.27, \eta_{p}^{2}=0.054 ;$ Olig2 ${ }^{+} \mathrm{CC}^{+}$: $p_{\text {genotype }}=0.074, \eta_{p}^{2}=0.15$ ). Assessment of astrogliosis (GFAP staining; Fig. $4 H$ quantitated in $I$; $p_{\text {genotype }}=0.38, \eta_{p}^{2}=0.070$ ) and microgliosis (Ibal staining; Fig. $4 H$ quantitated in $J ; p_{\text {genotype }}=$ $0.47, \eta_{p}^{2}=0.048$ ) also exhibited no differences between genotype in either unchallenged or cuprizone challenged conditions. These data indicate that oligodendroglial TrkB does not exert an essential role in oligodendroglial or myelin maintenance in the adult, or following cuprizone-induced demyelination

TDP6-enhanced oligodendrocyte differentiation is dependent on oligodendroglial TrkB

To determine whether the pro-remyelinating effects of TDP6 required oligodendrocyte expression of TrkB, we repeated the cuprizone experiments and $7 \mathrm{~d}$ osmotic pump infusions with 

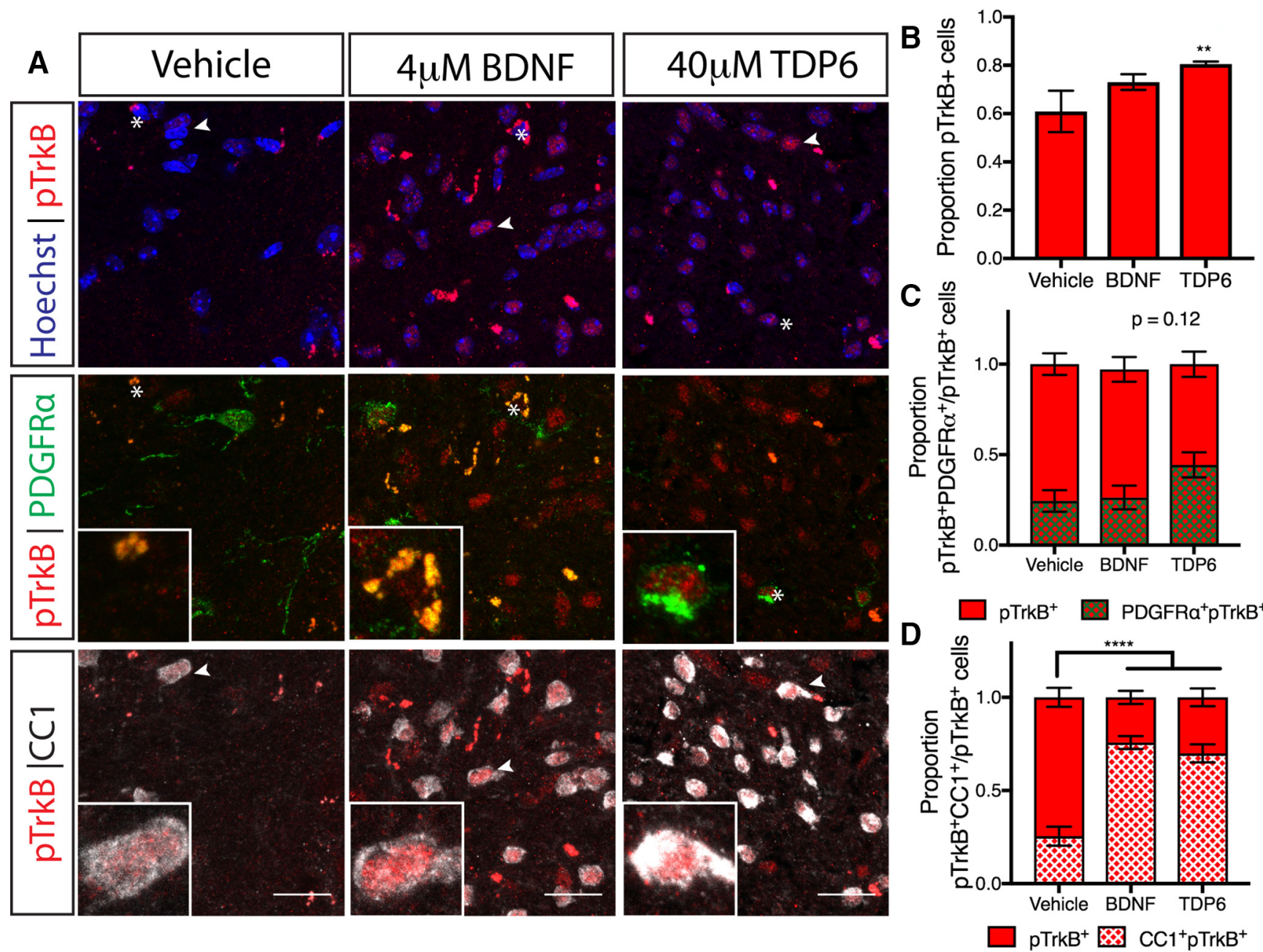

Figure 3. Treatment with TDP6 increased TrkB phosphorylation in the remyelinating corpus callosum. $A$, Representative micrographs of pTrkB ${ }^{5478}$ immunostaining in the caudal region of the corpus callosum. Scale bar, $20 \mu \mathrm{m}$. Asterisk, PDGFR $\alpha^{+}$cell featured in inset; arrowhead, $\mathrm{CC}^{+}{ }^{+}$cell featured in inset. B, Proportion of pTrkB ${ }^{\text {s478+ }}{ }^{+}$cells in the caudal corpus callosum was increased with TDP6 treatment compared with BDNF and vehicle controls $\left({ }^{* *} p=0.0047\right)$. C, Proportion of pTrkB ${ }^{5478+}$ cells that were PDGFR $\alpha^{+}$OPCs tended toward an increase with TDP6 treatment $(p=$ 0.12). D, Proportion of $\mathrm{pTrkB}^{\mathrm{S478}+}$ cells that were $\mathrm{CC}^{+}{ }^{+}$oligodendrocytes significantly increased with both BDNF and TDP6 treatment. $\boldsymbol{B}-\boldsymbol{D}, n=7-9 /$ group, one-way ANOVA with Tukey's post hoc multiple comparisons. Mean \pm SEM plotted.

either TDP6 $(n=4)$ or vehicle $(n=3)$ in CNPaseCre ${ }^{+/-} \times$ $\operatorname{TrkB}^{\mathrm{fl} / \mathrm{fl}}$ conditional knock-out mice. Immunohistochemistry for MBP (Fig. 5A) revealed the pro-remyelinating effect exerted by TDP6 in wild-type mice was lost, with both vehicle and TDP6treated conditional knock-out mice exhibiting the same level of MBP staining (Fig. $5 B ; p=0.45, d=0.63 \pm 0.78$ ). Further, the density of total Olig2 ${ }^{+}$oligodendroglia was also unchanged following TDP6 treatment (Fig. $5 C ; p=0.55, d=0.71 \pm 0.79$ ) and there was no change in the density of Olig $2^{+}$PDGFR $\alpha{ }^{+}$OPCs or Olig $2{ }^{+} \mathrm{CC}^{+}$oligodendrocytes between treatment groups in the conditional knock-out mice (Fig. $5 D, E ; p=0.80, d=0.26 \pm 0.77$ and $p=0.17, d=1.59 \pm 0.87$, respectively). These data suggest the effect TDP6 exerts to promote remyelination and increase oligodendrocyte density is dependent on oligodendrocyte expressed TrkB.

Successful delivery of TDP6 was confirmed by immunohistochemistry for $\mathrm{pTrkB}^{\mathrm{S} 478}$ (Fig. $5 F$ ) which revealed that the proportion of total $\mathrm{pTrkB}^{\mathrm{S} 478+}$ cells in the corpus callosum significantly increased in conditional knock-out mice that received TDP6, compared with those receiving the vehicle (Fig. 5G; $\left.{ }^{*} p=0.037, d=0.10 \pm 0.76\right)$. Consistent with reduced levels of TrkB expression in the CNPaseCre ${ }^{+/-} \operatorname{TrkB}^{\mathrm{fl} / \mathrm{fl}}$ mice, there was a low proportion of $\mathrm{pTrkB}^{\mathrm{S} 478+}$ PDGFR $\alpha^{+}$OPCs (Fig. $5 H$ ) and $\mathrm{pTrkB}^{\mathrm{S} 478+} \mathrm{CC}^{+}{ }^{+}$oligodendrocytes (Fig. 5I), and these were unchanged by treatment with TDP6 $(p=0.80, d=0.0065 \pm 0.76$ and $p=0.25, d=0.14 \pm 0.76$, respectively). Delivery of TDP6 was further verified by pooling residual TDP6-solution remaining in the osmotic pump reservoir at the end of the treatment period from the conditional knock-out mice, and run through reverse-phase HPLC (Fig. 6). This demonstrated that TDP6 was stable within the reservoir throughout the treatment period (Fig. $6 A-D)$.

Despite no change in MBP staining, EM analysis (Fig. 7A) revealed that the proportion of axons remyelinated in the caudal corpus callosum was significantly increased with TDP6 treatment in conditional knock-out mice (Fig. $7 D ;{ }^{\star} p=0.031, d=4.50 \pm$ 1.53). However, the mean g-ratio was unchanged (Vehicle: $0.74 \pm 0.02$; TDP6: $0.75 \pm 0.02, n=3$ group, $p=0.76, d=$ $0.015 \pm 0.82)$, indicating that whereas TDP6 increased the proportion of myelinated axons, it exerted no effect on myelin sheath thickness in the conditional knock-out mice. Linear regression analysis revealed that compared with vehicle treatment, TDP6 in the conditional knock-out mice resulted in a significant increase in slope (Fig. $7 B ; p<0.0001$ ), suggestive of an altered relation- 

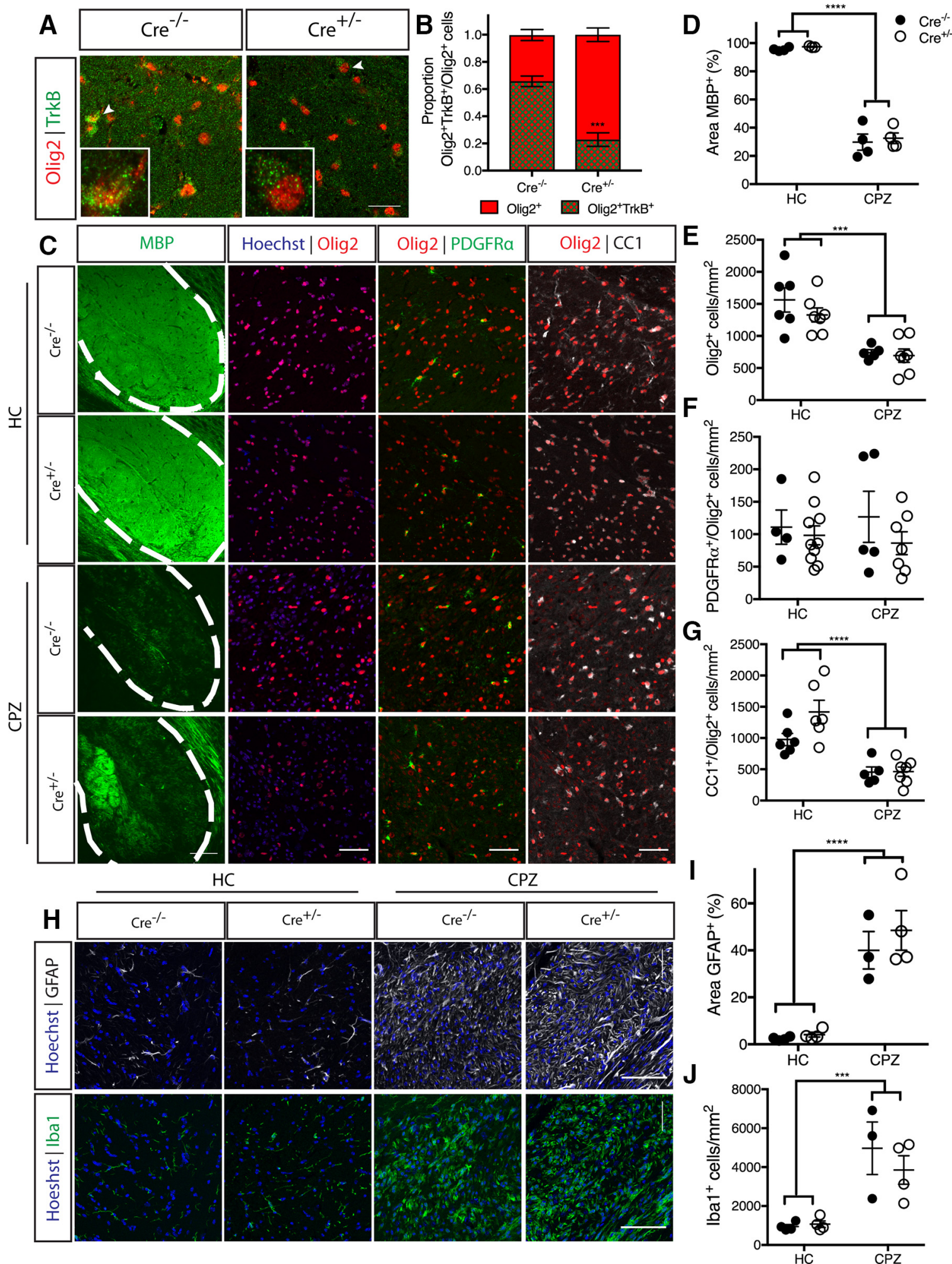

Figure 4. CNPaseCre ${ }^{+/-} \times \operatorname{TrkB}^{\mathrm{fl} / \mathrm{fl}}$ mice exhibit normal adult myelination and response to cuprizone-demyelination. $A$, Representative micrographs of TrkB and 0 lig2 immunostaining in the caudal corpus callosum of CNPaseCre ${ }^{-/-}$and CNPaseCre ${ }^{+/-}$TrkB $^{\mathrm{fl} / \mathrm{fl}}$ healthy controls aged 16 weeks. Scale bar, $20 \mu \mathrm{m}$. B, Proportion of Olig2 ${ }^{+}$cells positive for TrkB was significantly decreased in CNPaseCre ${ }^{+/-}$TrkB $^{\mathrm{fl} / \mathrm{fl}}$ mice compared with $\mathrm{Cre}^{-/-}$controls. Student's $t$ test, $n=4-6 /$ group. ${ }^{* * *} p=0.0003$. Mean \pm SEM plotted. C, Representative micrographs of immunostaining for MBP and oligodendrocyte lineage markers Olig2, PDGFR $\alpha$, and CC1 in the caudal corpus callosum of CNPaseCre ${ }^{-1-}$ (closed circles) and CNPaseCre ${ }^{+/-}$(open circles) TrkB $\mathrm{F}^{\mathrm{f} / \mathrm{fl}}$ healthy controls (HC), and cuprizone-fed (CPZ) mice. Scale bar, $50 \mu \mathrm{m}$. D, Area of MBP immunostaining and $(\boldsymbol{E})$ Olig2 ${ }^{+}$cell density were unchanged due to genotype in the healthy controls, but were significantly decreased in both genotypes following cuprizone treatment $\left({ }^{* * * *} p<0.0001\right.$ and ${ }^{* * *} p<0.001$, respectively). $F$, Density of 0 lig2 ${ }^{+}$PDGFR $\alpha^{+}$OPCs was unchanged with cuprizone treatment or genotype $(p=0.94) . \mathbf{G}, 0$ lig2 ${ }^{+} \mathrm{CC} 1^{+}$oligodendrocytes were unchanged between genotypes in healthy controls, while cuprizone feeding significantly reduced the density of these cells in the caudal corpus callosum of both genotypes $\left.{ }^{* * * *} p<0.0001\right)$. $\boldsymbol{H}$, Representative micrographs of GFAP ${ }^{+}$astrocytosis and Iba ${ }^{+}$microglia in the caudal corpus callosum of Cre ${ }^{-/-}$and $\mathrm{Cre}{ }^{+/-} \mathrm{HC}$ and CPZ mice. Scale bar, $50 \mu \mathrm{m}$. I, Percentage area $\mathrm{GFAP}^{+}$and $(\boldsymbol{J})$ density of $\mathrm{lba} 1^{+}$microglia were similar in both genotypes in $\mathrm{HC}$, and were increased in both genotypes following $\mathrm{CPZ}\left({ }^{* * * *} \mathrm{P}<\right.$ $\left.0.0001,{ }^{* * *} p=0.0003\right) . D-G, I, J, n=3-7 /$ group, two-way ANOVA. 


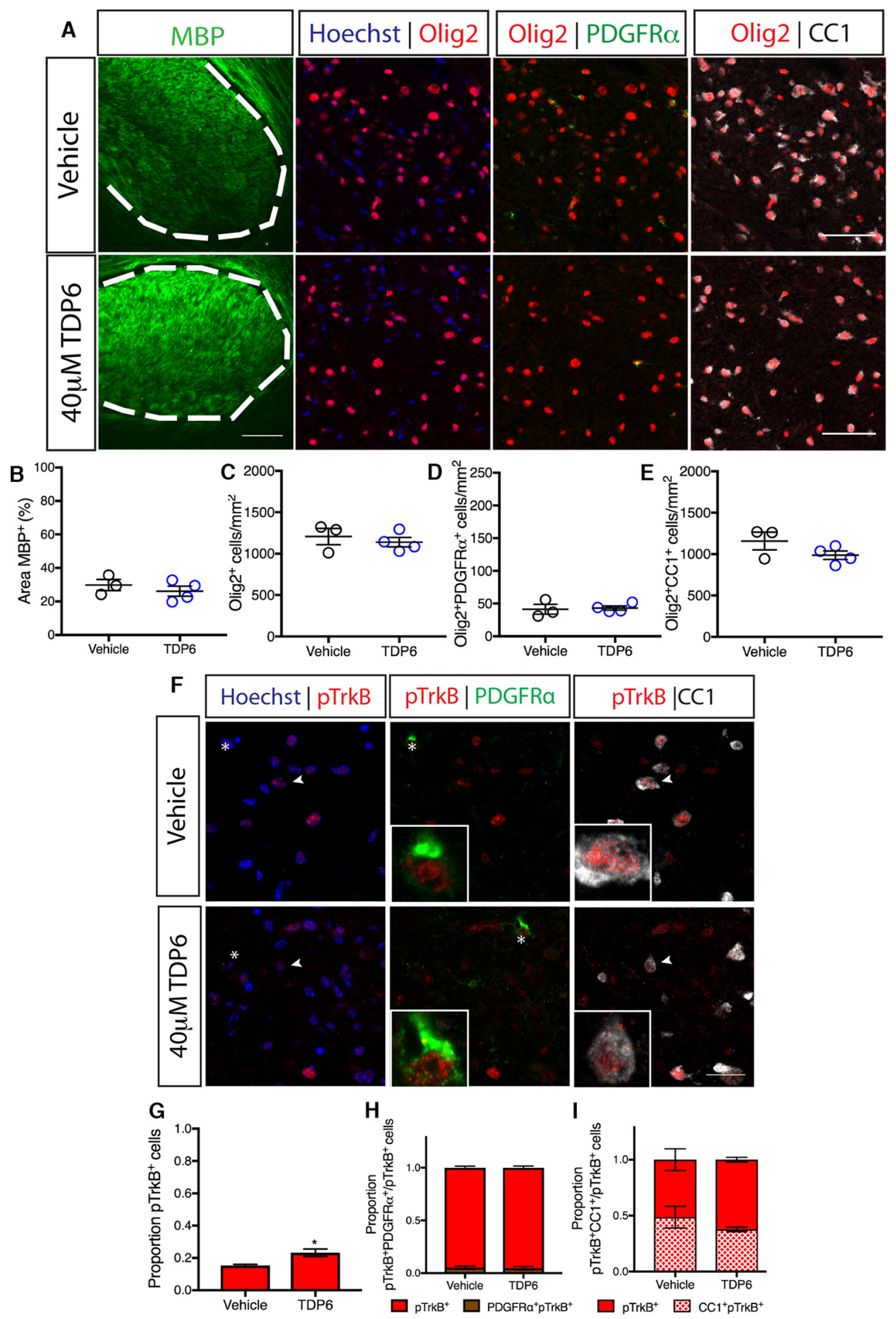

Figure 5. Enhanced oligodendrocyte differentiation by TDP6 during remyelination requires oligodendrocyte TrkB. $A$, Representative micrographs of MBP immunostaining and oligodendrocyte

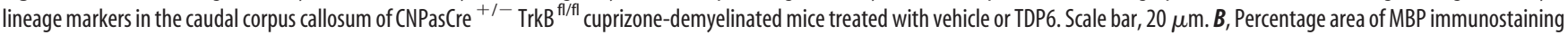
$(p=0.45)$, density of $(\boldsymbol{C})$ 0lig2 ${ }^{+}$cells $(p=0.55)$, (D) 0lig2 ${ }^{+}$PDGFR $\alpha^{+}$OPCs $(p=0.80)$, and $(\boldsymbol{E}) 0$ lig $2^{+} C\left(1^{+}\right.$oligodendrocytes $(p=0.17)$ were unchanged between vehicle and TDP6-treated TrkB conditional knock-out mice. Unpaired Student's $t$ test, $n=3-4 /$ group. $F$, Representative micrographs of pTrkB ${ }^{\text {S478 }}$ immunostaining in the caudal corpus callosum of CNPaseCre ${ }^{+/-}$TrkB $^{\mathrm{f} / \text { fl }}$ cuprizone-demyelinated mice treated with vehicle or TDP6. Scale bar, $20 \mu \mathrm{m}$. G, Proportion of pTrkB ${ }^{\text {S478+ }}$ cells were significantly increased in TDP6-treated conditional knock-out mice ( $p=$ $0.037)$, but $(\boldsymbol{H})$ the proportion of pTrkB ${ }^{5478+}$ PDGFR $\alpha^{+}$OPCs were unchanged $(p=0.80)$ as were $(\boldsymbol{I})$ the proportion of pTrkB ${ }^{5478+} C\left(1^{+}\right.$oligodendrocytes $(p=0.25)$. Unpaired Student's $t$ test, $n=3-4 /$ group.

ship between myelin profiles and axonal diameter. To dissect the driver of this effect, g-ratios were categorized based on axon diameter. This revealed that there was no change in myelin sheath thickness across axons of different diameter (Fig. 7E), suggesting the change in slope was likely driven by an increase in the number of axons myelinated in each size category between treatments. Consistent with this, analysis of the frequency distribution of myelinated axons based on their diameter demonstrated that 

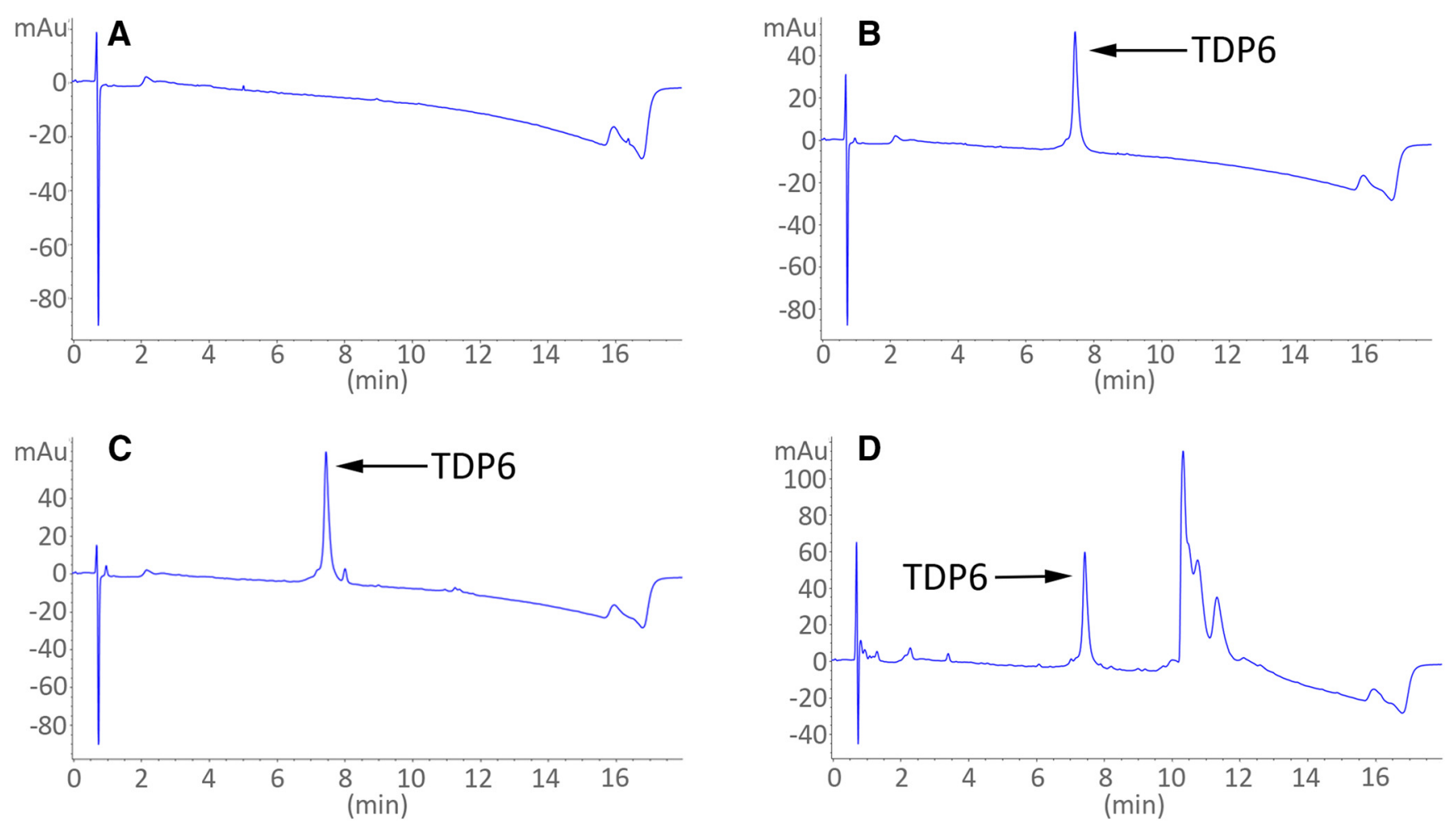

Figure 6. TDP6 was retrieved and detected after 7 incubation within osmotic minipumps implanted in conditional knock-out mice. $A$, Reverse-phase HPLC UV trace of aCSF ("blank/control" sample). B, HPLC UV trace of TDP6 at day before animal administration. C, HPLC UV trace of TDP6 at day 0. D, HPLC UV trace of TDP6 at day 7. All traces measured using $214 \mathrm{~nm}$ wavelength. Note: Additional peak in $\boldsymbol{D}$ was determined not to be a peptide degradation product. Area under the peptide peak was quantified in $\boldsymbol{B}-\boldsymbol{D}$ and no significant change was observed.

there were significantly more axons between 0.3 and $0.6 \mu \mathrm{m}$ range that were myelinated in TDP6-treated conditional knockout mice (Fig. $7 F ;{ }^{*} p=0.0032$ ). Examination of the motor cortex (M2) in available sections ( $n=2$ /group) indicated that there was a trend toward more $p \operatorname{TrkB}{ }^{S 478}$-positive neurons in TDP6treated conditional knock-out mice (Fig. 7C). Collectively, these data suggest that TDP6 may exert a small oligodendroglial-TrkB independent effect to initiate myelin ensheathment for a selective subset of axons, but not increase myelin sheath thickness.

\section{Discussion}

Selective targeting of TrkB with the BDNF mimetic, TDP6 in the cuprizone-demyelinated brain enhanced remyelination. TDP6 increased the density of Olig $2{ }^{+} \mathrm{CC}^{+}{ }^{+}$oligodendrocytes, proportion of remyelinated axons, and myelin sheath thickness following $7 \mathrm{~d}$ recovery. Infusion with BDNF, the neurotrophin from which TDP6 is derived, demonstrated an attenuated response, only increasing myelin sheath thickness. Importantly, the effects of TDP6 on myelin sheath thickness and oligodendrocyte differentiation required oligodendroglial TrkB. Intriguingly, following deletion of TrkB from oligodendroglia, TDP6 retained some capacity to increase the proportion of remyelinated axons. This may be due to the action of TDP6 on non-recombined oligodendroglial cells. However, TDP6 is not targeted toward specific cell types, and there is also the possibility that TDP6 may activate alternate sources of TrkB, potentially neuronal, to initiate myelin ensheathment, effectively increasing frequency of remyelinated axons.

The therapeutic potential of BDNF has been tested in numerous intervention studies and clinical trials for neurologic conditions over the past several decades (McTigue et al., 1998; The BDNF Study Group, 1999; Fulmer et al., 2014; Ramos-Cejudo et al., 2015). In demyelinating diseases, direct infusion (Ramos-
Cejudo et al., 2015), cell-based gene therapy to overexpress BDNF (McTigue et al., 1998), and indirect modulation of endogenous BDNF secretion (Fulmer et al., 2014) in animal models have shown promise. However, by and large, these studies used indirect measures of remyelination, such as OPC proliferation and increased expression of myelin proteins, MBP, MOG, and PLP (McTigue et al., 1998; Fulmer et al., 2014; Ramos-Cejudo et al., 2015). Here, direct BDNF infusion to the demyelinated CNS increased MBP expression, and tended to increase OPC density, consistent with previous reports (McTigue et al., 1998; Fulmer et al., 2014; Ramos-Cejudo et al., 2015), but did not increase the proportion of myelinated axons, or oligodendrocyte differentiation. These abilities are essential to a remyelinating strategy, particularly for MS where OPC differentiation appears arrested (Chang et al., 2002). In contrast, by targeting TrkB, the direct molecular mechanism used by BDNF to promote myelination in development (Xiao et al., 2010; Wong et al., 2013), we increased the density of Olig $2{ }^{+} \mathrm{CC}^{+}$oligodendrocytes and the proportion of myelinated axons.

It is well appreciated that BDNF promotes CNS myelination through activation of oligodendroglial TrkB (Xiao et al., 2010; Wong et al., 2013). We found selective targeting of TrkB with TDP6, led to greater TrkB phosphorylation in the corpus callosum, more mature oligodendrocytes, and higher frequency of remyelinated axons than exogenous BDNF. Why TDP6 elicited this significantly greater remyelinating effect remains unclear. Deductive reasoning suggests potential differences in specificity, stability, dosage, or a combination of all three, may contribute to this discrepancy. The concentrations used were based on previous in vitro myelinating cocultures where 25 -fold more TDP6 was required to increase the number of $\mathrm{MBP}^{+}$myelinated axonal segments to the same level as BDNF, and induce TrkB and Erk1/2 
A
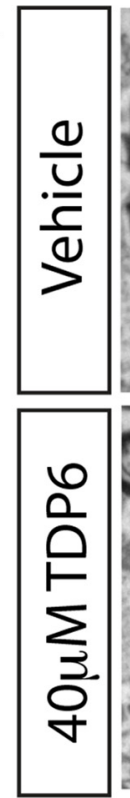

D

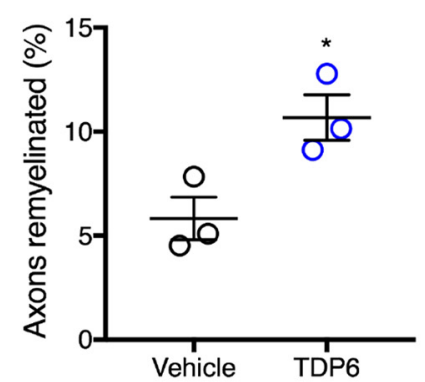

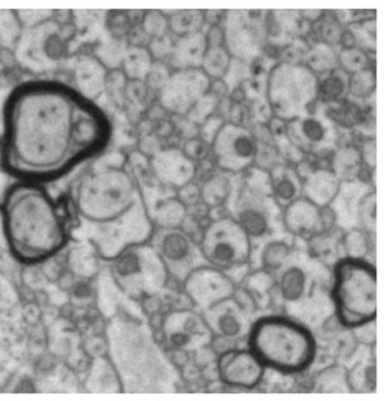

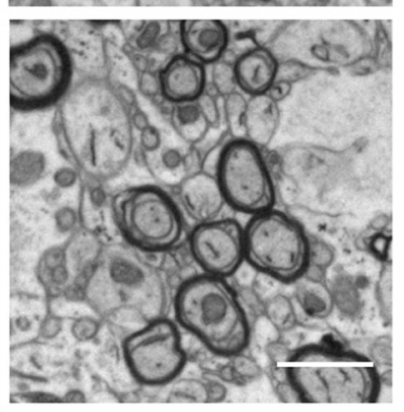

E
B

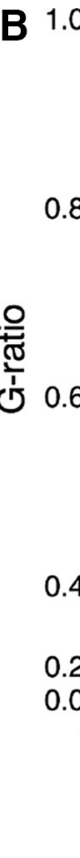

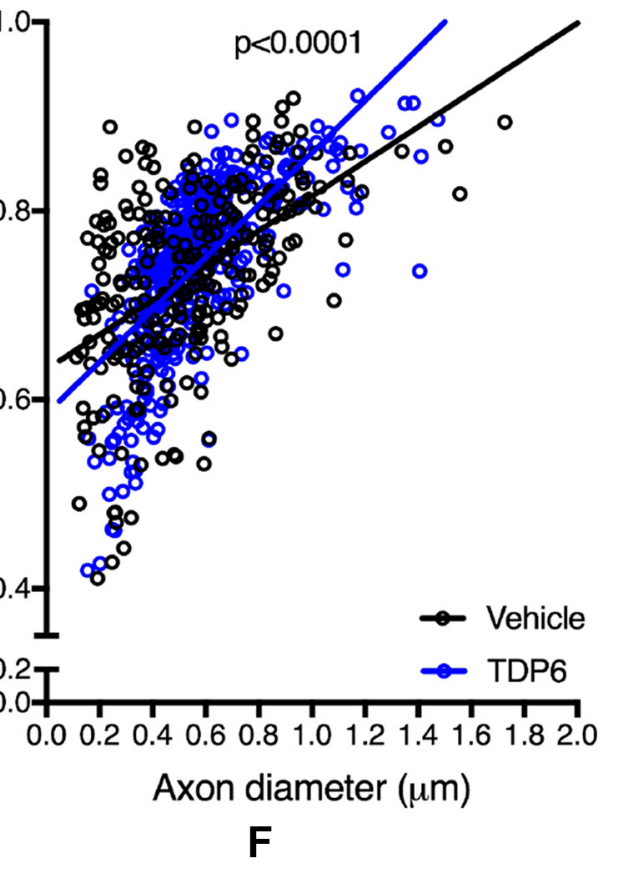
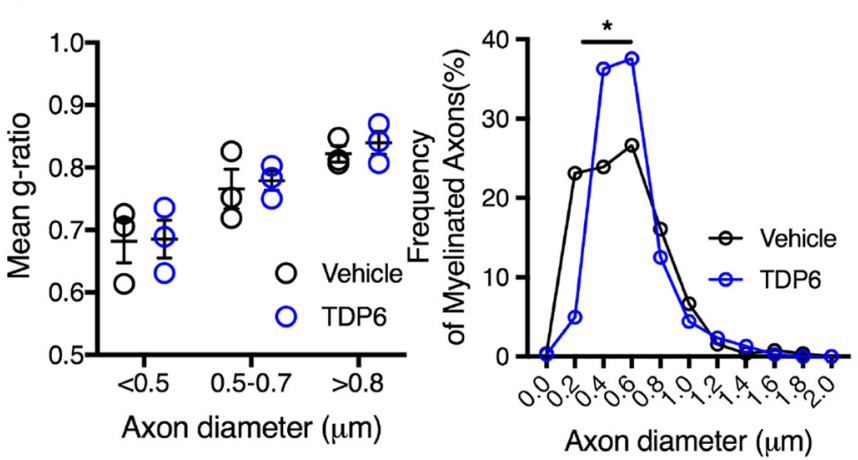

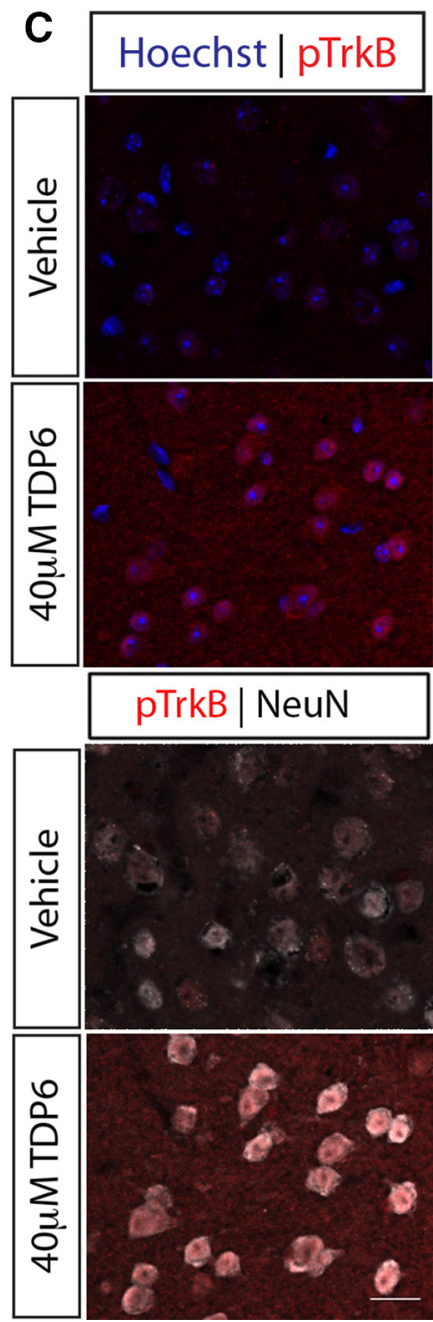

Figure 7. Increases in myelin sheath thickness by TDP6 requires oligodendrocyte TrkB. $A$, Electron micrographs of the caudal corpus callosum of CNPaseCre ${ }^{+/-}$TrkB $^{\text {fl/fl }}$ cuprizone-demyelinated mice treated with vehicle or TDP6. Scale bar, $1 \mu \mathrm{m}$. B, Scatter plot of g-ratio against axon diameter. Linear regression analysis revealed a significant increase in slope between CNPaseCre ${ }^{+/-}$ $\mathrm{TrkB}^{\mathrm{fl} / \mathrm{fl}}$ mice treated with TDP6 compared with vehicle. C, Representative micrographs of pTrkBS478 in the M2 cortex (top) and colabeled with neuronal marker NeuN (bottom). $\boldsymbol{D}$, Proportion of myelinated axons was significantly increased in TrkB conditional knock-out mice that received TDP6 compared with vehicle controls $\left({ }^{*} p=0.0314\right)$. $\boldsymbol{E}$, Mean $g$-ratio categorized by axonal diameter revealed no significant change between treatment groups, indicative of no change in myelin sheath thickness with TDP6 treatment in TrkB conditional knock-out mice $(p=0.959), n=3 /$ group, two-way ANOVA. $\boldsymbol{F}$, Frequency plot of myelinated axon diameters revealing a significant increase in the frequency of axons myelinated ranging from 0.3 to $0.6 \mu \mathrm{m}$ diameter in CNPaseCre ${ }^{+/-}$ $\operatorname{TrkB}^{\mathrm{fl} / \mathrm{fl}}$ mice treated with $\operatorname{TDP6}\left(p=0.0032, \chi^{2}\right.$ distribution test). $\boldsymbol{B}, \boldsymbol{D}-\boldsymbol{F}$, Minimum 100 axons/animal, $n=3 /$ group.

phosphorylation (Wong et al., 2014). From this, BDNF is substantially more potent than TDP6, suggesting the lower concentration of BDNF unlikely caused the attenuated response. The notoriously labile and highly charged nature of BDNF may contribute to its reduced efficacy in vivo. BDNF has a very short half-life (Poduslo and Curran, 1996), although we have shown that TDP6 can be retrieved from osmotic pump reservoirs after $7 \mathrm{~d}$ in vivo. Finally, the receptor specificity may also play a role. TDP6 selectively interacts with TrkB and has not shown any ability to interact with p $75^{\text {NTR }}$ (O'Leary and Hughes, 2003; Xiao et al., 2010; Wong et al., 2014). It is possible that BDNF-p75 ${ }^{\text {NTR }}$ interactions attenuate the BDNF response. Regardless, the attenuated remyelinating response to $\mathrm{BDNF}$ is consistent with reduced TrkB phosphorylation observed compared with TDP6. Importantly, compared with other BDNF-mimetics (Jiang et al., 2013; Simmons et al., 2013), we have shown using conditional knockout mice, the effects of TDP6 are predominantly dependent on TrkB expression by the target cell in vivo. This is the first time the effect of a neurotrophin mimetic has been identified to require its targeted receptor on a specific cell type. Overall, our results dem- onstrate the poor therapeutic potential of BDNF, and support the strategy to develop functional BDNF mimics as therapies for neurologic disease.

A feature consistent with BDNF and TDP6 treatment was increased myelin sheath thickness, indicated by reduced g-ratios. This is the first time exogenous BDNF has been demonstrated to affect the myelin sheath in vivo. A role for BDNF in modulating myelin sheath thickness is not unexpected. $\mathrm{BDNF}^{-1-}, \mathrm{BDNF}^{+/-}$ and $\mathrm{MBPCre}{ }^{+/-\times} \operatorname{TrkB}^{\mathrm{f} / \mathrm{fl}}$ mice all demonstrate developmental hypomyelination with thinner myelin compared with wild-type mice (Cellerino et al., 1997; Xiao et al., 2010; Wong et al., 2013). In addition, BDNF-TrkB signaling activates the MAPK/Erk pathway (Du et al., 2006; Xiao et al., 2012), which in oligodendrocytes increases myelin sheath thickness (Ishii et al., 2012, 2016; FyffeMaricich et al., 2013). The effect BDNF and TDP6 exert on myelin sheath thickness requires oligodendroglial TrkB expression, as there was no change in g-ratio when TDP6 was delivered in the conditional knock-out mice.

Similarly, the effect TDP6 exerted to increase oligodendrocyte density required oligodendroglial TrkB. It is unclear whether this 
effect is due to $\operatorname{TrkB}$ stimulation of OPC proliferation, or enhanced survival. A role for BDNF in OPC proliferation has been suggested, with reduced OPC proliferation exhibited in $\mathrm{BDNF}^{+/-}$mice following cuprizone demyelination (VonDran et al., 2011; Fulmer et al., 2014). Despite reduced OPC proliferation, the density of mature oligodendrocytes was unchanged between $\mathrm{BDNF}^{+/-}$and wild-type mice following recovery (VonDran et al., 2011). Deletion of TrkB from maturing oligodendrocytes in development causes OPC hyperproliferation, but this too, exerts no effect on the density of mature oligodendrocytes in adulthood (Wong et al., 2013). Collectively, these data suggest BDNF-TrkB signaling is not essential for oligodendrocyte differentiation, but rather TrkB activation regulates OPC proliferation in vivo. Labeling proliferating cells at the time of cuprizone withdrawal and TDP6 delivery in wild-type and conditional knock-out mice would determine whether TrkB signaling exerts a controlling influence upon OPC proliferation following myelin injury. Given the increase in Olig2 ${ }^{+} \mathrm{CC}^{+}$oligodendrocytes in response to TDP6 depended on oligodendroglial expression of TrkB, sustained levels TrkB activation may also override apoptotic signals. This would enhance OPC survival, increasing the density of differentiated oligodendrocytes. Regardless, the ultimate fate and persistence of all Olig2 ${ }^{+} \mathrm{CCl}^{+}$oligodendrocytes produced by TDP6 treatment in the long-term remyelinating CNS, as well as the incorporation and persistence of the thicker myelin sheath generated by these cells is a pertinent question to be answered in the context of chronic demyelination in MS.

Intriguingly, although deletion of TrkB from oligodendrocytes abrogated the effects of TDP6 on myelin sheath thickness and oligodendrocyte differentiation, the proportion of myelinated axons still increased. This suggests TDP6 may have effects independent of oligodendroglial TrkB. No significant effect of TDP6 on astrogliosis and microgliosis suggests TDP6 does not directly modulate these cell populations, although it may alter the composition of their secreted factors (Djalali et al., 2005). It is also possible increased myelination in TDP6-treated conditional knock-out mice was mediated by a small subset of oligodendrocytes that escape recombination and continue to express TrkB. This view would be consistent with previous work by us (Xiao et al., 2011; Wong et al., 2013) and others (Minichiello et al., 1999; Medina et al., 2004) indicating the role of TrkB in CNS myelination is specific to oligodendrocytes. However, what is striking is that the increase in myelinated axons in TDP6-treated conditional knock-out mice was driven by an increase in the frequency of small diameter axons $(0.3-0.6 \mu \mathrm{m})$ becoming myelinated. This is suggestive of a selective axonal response driving initiation of myelination on this axonal subpopulation. The recent focus on activity-dependent myelination has indicated efficient remyelination, on small diameter axons in particular, may require neuronal signals (Gautier et al., 2015; Bechler et al., 2018). Optogenetic stimulation of cortical neurons increased neuronal secretion of BDNF (Venkatesh et al., 2015), and this manipulation in healthy cortex increased callosal myelination (Gibson et al., 2014). This suggests a possible role for neuronally derived autocrine BDNF-TrkB signaling in adaptive myelination, and importantly remyelination (Lundgaard et al., 2013). This potential role for neuronally-derived TrkB in promoting remyelination may be fortuitous. TrkB expression is found in neurons adjacent to demyelinated lesions in MS (Stadelmann et al., 2002) and could be directly targeted with TDP6, or by other indirect strategies to sustain TrkB phosphorylation and remyelination. The mechanism mediating the TDP6-dependent increase in the frequency of myelinated axons in conditional knock-out mice is unclear.
Adoption of neuronal TrkB knock-out strategies will ultimately confirm whether neuronal TrkB directly influences remyelination, or whether this effect is due to an indirect response stimulated by TDP6.

We demonstrated that TDP6, a structural mimetic of the TrkB binding region of BDNF, enhances remyelination in a preclinical animal model of MS. By targeting TrkB after demyelination, oligodendrocyte differentiation, the proportion of myelinated axons, and myelin sheath thickness all increased. These are key outcomes for a potential remyelinating strategy. Deletion of TrkB from oligodendrocytes abrogated the effect of TDP6 on myelin sheath thickness and oligodendrocyte differentiation, but an increase in myelinated axons persisted, revealing a potential for targeting additional non-oligodendrocyte-specific effects of TrkB in remyelination. Overall, our results support the development of therapeutic strategies to sustain elevations of TrkB signaling to promote myelin repair in demyelinating disease.

\section{References}

Albert M, Antel J, Brück W, Stadelmann C (2007) Extensive cortical remyelination in patients with chronic multiple sclerosis. Brain Pathol 17:129138. CrossRef Medline

Bechler ME, Swire M, Ffrench-Constant C (2018) Intrinsic and adaptive myelincation - a sequential mechanism for smart wiring in the brain. Dev Neurobiol 78:68-79. CrossRef Medline

Cellerino A, Carroll P, Thoenen H, Barde YA (1997) Reduced size of retinal ganglion cell axons and hypomyelination in mice lacking brain-derived neurotrophic factor. Mol Cell Neurosci 9:397-408. CrossRef Medline

Chang A, Tourtellotte WW, Rudick R, Trapp BD (2002) Premyelinating oligodendrocytes in chronic lesions of multiple sclerosis. N Engl J Med 346:165-173. CrossRef Medline

Chao MV (2003) Neurotrophins and their receptors: a convergence point for many signalling pathways. Nat Rev Neurosci 4:299-309. CrossRef Medline

Djalali S, Höltje M, Große G, Rothe T, Stroh T, Große J, Deng DR, Hellweg R, Grantyn R, Hörtnagl H, Ahnert-Hilger G (2005) Effects of brainderived neurotrophic factor (BDNF) on glial cells and serotonergic neurones during development. J Neurochem 92:616-627. CrossRef Medline

Du Y, Fischer TZ, Lee LN, Lercher LD, Dreyfus CF (2003) Regionally specific effects of BDNF on oligodendrocytes. Dev Neurosci 25:116-126. CrossRef Medline

Du Y, Lercher LD, Zhou R, Dreyfus CF (2006) Mitogen-activated protein kinase pathway mediates effects of brain derived neurotrophic factor on basal forebrain oligodendrocytes. J Neurosci Res 84:1692-1702. CrossRef Medline

Fletcher JL, Kondagari GS, Vite CH, Williamson P, Taylor RM (2014) Oligodendrocyte loss during the disease course in a canine model of the lysosomal storage disease fucosidosis. J Neuropathol Exp Neurol 73:536547. CrossRef Medline

Fulmer CG, VonDran MW, Stillman AA, Huang Y, Hempstead BL, Dreyfus CF (2014) Astrocyte-derived BDNF supports myelin protein synthesis after cuprizone-induced demyelination. J Neurosci 34:8186-8196. CrossRef Medline

Fyffe-Maricich SL, Schott A, Karl M, Krasno J, Miller RH (2013) Signaling through ERK1/2 controls myelin thickness during myelin repair in the adult central nervous system. J Neurosci 33:18402-18408. CrossRef Medline

Gautier HO, Evans KA, Volbracht K, James R, Sitnikov S, Lundgaard I, James F, Lao-Peregrin C, Reynolds R, Franklin RJ, Káradóttir RT (2015) Neuronal activity regulates remyelination via glutamate signalling to oligodendrocyte progenitors. Nat Commun 6:8518. CrossRef Medline

Gibson EM, Purger D, Mount CW, Goldstein AK, Lin GL, Wood LS, Inema I, Miller SE, Bieri G, Zuchero JB, Barres BA, Woo PJ, Vogel H, Monje M (2014) Neuronal activity promotes oligodendrogenesis and adaptive myelinaton in the mammalian brain. Science 344:1252304. CrossRef Medline

Ishii A, Fyffe-Maricich SL, Furusho M, Miller RH, Bansal R (2012) ERK1/ ERK2 MAPK signaling is required to increase myelin thickness independent of oligodendrocyte differentiation and initiation of myelination. J Neurosci 32:8855-8864. CrossRef Medline 
Ishii A, Furusho M, Dupree JL, Bansal R (2016) Strength of ERK1/2 MAPK activation determines its effect on myelin and axonal integrity in the adult CNS. J Neurosci 36:6471-6487. CrossRef Medline

Jiang M, Peng Q, Liu X, Jin J, Hou Z, Zhang J, Mori S, Ross CA, Ye K, Duan W (2013) Small-molecule TrkB receptor agonists improve motor function and extend survival in a mouse model of huntington's disease. Hum Mol Genet 22:2462-2470. CrossRef Medline

Lappe-Siefke C, Goebbels S, Gravel M, Nicksch E, Lee J, Braun PE, Griffiths IR, Nave KA (2003) Disruption of Cnp1 uncouples oligodendroglial functions in axonal support and myelination. Nat Genet 33:366-374. CrossRef Medline

Legland D, Arganda-Carreras I, Andrey P (2016) MorphoLibJ: integrated library and plugins for mathematical morphology with ImageJ. Bioinformatics 32:3532-3534. CrossRef Medline

Longo FM, Massa SM (2013) Small-molecule modulation of neurotrophin receptors: a strategy for the treatment of neurological disease. Nat Rev Drug Discov 12:507-525. CrossRef Medline

Lucchinetti C, Brück W, Parisi J, Scheithauer B, Rodriguez M, Lassmann H, Bruck W, Parisi JE, Scheithauer B, Rodriguez M, Lassmann H (1999) A quantitative analysis of oligodendrocytes in multiple sclerosis lesions. Brain 122:2279-2295. CrossRef Medline

Lulkart BW, Net S, Virmani T, Lush ME, Liu Y, Kavalali ET, Parada LF (2005) TrkB has a cell-autonomous role in the establishment of hippocampal Schaffer collateral synapses. J Neurosci 25:3774-3786. CrossRef Medline

Lundgaard I, Luzhynskaya A, Stockley JH, Wang Z, Evans KA, Swire M, Volbracht K, Gautier HO, Franklin RJ, ffrench-Constant C, Attwell D, Káradóttir RT (2013) Neuregulin and BDNF induce a switch to NMDA receptor-dependent myelination by oligodendrocytes. PLoS Biol 11: e1001743. CrossRef Medline

McTigue DM, Horner PJ, Stokes BT, Gage FH (1998) Neurotrophin-3 and brain-derived neurotrophic factor induce oligodendrocyte proliferation and myelination of regenerating axons in the contused adult rat spinal cord. J Neurosci 18:5354-5365. CrossRef Medline

Medina DL, Sciarretta C, Calella AM, Von Bohlen Und Halbach O, Unsicker K, Minichiello L (2004) TrkB regulates neocortex formation through the Shc/PLC $\gamma$-mediated control of neuronal migration. EMBO J 23: 3803-3814. CrossRef Medline

Minichiello L, Korte M, Wolfer D, Kühn R, Unsicker K, Cestari V, RossiArnaud C, Lipp HP, Bonhoeffer T, Klein R (1999) Essential tole for TrkB receptors in hippocampus-mediated learning. Neuron 24:401-414. CrossRef Medline

O'Leary PD, Hughes RA (2003) Design of potent peptide mimetics of brainderived neurotrophic factor. J Biol Chem 278:25738-25744. CrossRef Medline

Paxinos G, Franklin KBJ (2001) The mouse brain in stereotaxic coordinates, Ed 2. London: Academic.
Poduslo JF, Curran GL (1996) Permeability at the blood-brain and bloodnerve barriers of the neurotrophic factors: NGF, CNTF, NT-3, BDNF. Brain Res Mol Brain Res 36:280-286. CrossRef Medline

Ramos-Cejudo J, Gutiérrez-Fernández M, Otero-Ortega L, Rodríguez-Frutos B, Fuentes B, Vallejo-Cremades MT, Hernanz TN, Cerdán S, DíezTejedor E (2015) Brain-derived neurotrophic factor administration mediated oligodendrocyte differentiation and myelin formation in subcortical ischemic stroke. Stroke 46:221-228. CrossRef Medline

Simmons DA, Belichenko NP, Yang T, Condon C, Monbureau M, Shamloo M, Jing D, Massa SM, Longo FM (2013) A small molecule TrkB ligand reduces motor impairment and neuropathology in R6/2 and BACHD mouse models of Huntington's disease. J Neurosci 33:18712-18727. CrossRef Medline

Stadelmann C, Kerschensteiner M, Misgeld T, Brück W, Hohlfeld R, Lassmann H (2002) BDNF and gp145trkB in multiple sclerosis brain lesions: neuroprotective interactions between immune and neuronal cells? Brain 125:75-85. CrossRef Medline

Stangel M, Kuhlmann T, Matthews PM, Kilpatrick TJ (2017) Achievements and obstacles of remyelinating therapies in multiple sclerosis. Nat Rev Neurol 13:742-754. CrossRef Medline

The BDNF Study Group (Phase III) (1999) A controlled trial of recombinant methionyl human BDNF in ALS. Neurology 52:1427-1433. CrossRef Medline

Venkatesh HS, Johung TB, Caretti V, Noll A, Tang Y, Nagaraja S, Gibson EM, Mount CW, Polepalli J, Mitra SS, Woo PJ, Malenka RC, Vogel H, Bredel M, Mallick P, Monje M (2015) Neuronal activity promotes glioma growth through neuroligin-3 secretion. Cell 161:803-816. CrossRef Medline

VonDran MW, Singh H, Honeywell JZ, Dreyfus CF (2011) Levels of BDNF impact oligodendrocyte lineage cells following a cuprizone lesion. J Neurosci 31:14182-14190. CrossRef Medline

Wong AW, Xiao J, Kemper D, Kilpatrick TJ, Murray SS (2013) Oligodendroglial expression of TrkB independently regulates myelination and progenitor cell proliferation. J Neurosci 33:4947-4957. CrossRef Medline

Wong AW, Giuffrida L, Wood R, Peckham H, Gonsalvez D, Murray SS, Hughes RA, Xiao J (2014) TDP6, a brain-derived neurotrophic factorbased trkB peptide mimetic, promotes oligodendrocyte myelination. Mol Cell Neurosci 63:132-140. CrossRef Medline

Xiao J, Wong AW, Willingham MM, van den Buuse M, Kilpatrick TJ, Murray SS (2010) Brain-derived neurotrophic factor promotes central nervous system myelination via a direct effect upon oligodendrocytes. NeuroSignals 18:186-202. CrossRef Medline

Xiao J, Ferner AH, Wong AW, Denham M, Kilpatrick TJ, Murray SS (2012) Extracellular signal-regulated kinase 1/2 signaling promotes oligodendrocyte myelination in vitro. J Neurochem 122:1167-1180. CrossRef Medline 